\title{
An attenuation study in Southern Italy using local and regional earthquakes recorded by seismic network of Basilicata
}

\author{
Raúl Ramón Castro $\left({ }^{1}\right)$, Maria Rosaria Gallipoli $\left({ }^{2}\right)\left({ }^{3}\right)$ and Marco Mucciarelli $\left(^{3}\right)$ \\ (1) CICESE, División Ciencias de la Tierra, Departamento de Sismología, Ensenada, Baja California, México \\ ${ }^{2}{ }^{2}$ Istituto di Metodologie per l'Analisi Ambientale (IMAA) - CNR, Tito Scalo (PZ), Italy \\ ( $\left.{ }^{3}\right)$ Di.S.G.G., Università degli Studi della Basilicata, Potenza, Italy
}

\begin{abstract}
We determined a set of empirical functions that describe the spectral amplitude decay of $S$-waves with distance in Southern Italy. We analyzed 32 earthquakes with magnitudes $M_{L}$ 2.0-5.4 and hypocentral distances ranging between 12 and $216 \mathrm{~km}$. We obtained attenuation functions for 14 frequencies $(1.0<f<20.0 \mathrm{~Hz})$. We compared these functions with average non-parametric attenuation functions reported by Castro et al. (1999) for different regions of Italy, and we observe that at low frequencies $(f<5.0 \mathrm{~Hz})$ the spectral amplitudes from earthquakes in Southern Italy decay faster than the average. However, at high frequencies $(f>5.0 \mathrm{~Hz})$, the spectral amplitudes are above the average. At higher frequencies $(f>10 \mathrm{~Hz})$, the attenuation functions obtained for Southern Italy are slightly above the standard deviation of the average attenuation functions. It is possible that in this frequency range $(10-20 \mathrm{~Hz})$ site effects may influence the amplitude decay. In order to quantify the attenuation of the $S$-waves, we estimated the quality factor $Q$ modeling the empirical attenuation functions using the following parametric form: $A(f, r)=10 / r^{b} \cdot e^{-\pi f R / Q \beta}$; where $1.6 \leq f \leq 10.0 \mathrm{~Hz}$ is the frequency band with minimum effect of instrument and site response, $r \leq 120 \mathrm{~km}$ is the distance range where the rate of decay of the spectral amplitudes is approximately constant, $R=(r-10)$ and $\beta=3.2 \mathrm{~km} / \mathrm{s}$. We found that the exponent $b=1.0 \pm 0.2$ in the frequency band analyzed and $Q$ shows a frequency dependence that can be approximated by the function $Q=32.1 f^{1.7}$.
\end{abstract}

Key words seismic attenuation - Southern Italy $-Q$

\section{Introduction}

The main goal of this study is to find empirical attenuation functions that describe the spectral amplitude decay with distance using local and regional events located in Southern Italy. Southern Italy is a complex region, located at the boundary between the Apulia micro

Mailing address: Dr. Raúl Ramón Castro, CICESE, División Ciencias de la Tierra, Departamento de Sismología, km 107 carratera Tijuana-Ensenada, Ensenada, Baja California, 22860 México; e-mail: raul@ cicese.mx plate and the extensional Tyrrhenian Sea Basin (see e.g., Mantovani et al., 1996). Important volcanic activity has been related to the formation of the Tyrrhenian-Apennine system (Mele et al., 1997). Southern Italy is also a region with high seismic activity. Intermediate and deep seismicity has been associated to the subducting Apulia slab dipping toward the Tyrrhenian Basin (McKenzie, 1972; Gasparini et al., 1982). Shallow crustal seismicity is mainly concentrated along the Apenninic Chain, where normal faults trending NW-SE are separated by transfer zone with strike-slip seismicity (Valensise and Pantosti, 2001). Important historical events have also occurred, for instance the 1857 Val d'Agri $(M=7.0), 1980$ Irpinia $(M=6.9)$ earthquakes. The Tyrrhenian region is charac- 
terized by high $S$-wave attenuation in the crust and mantle and early $P$-wave arrivals (Caputo et al., 1972; Del Pezzo et al., 1979).

Because reliable characterization of seismic attenuation is important for seismic hazards and risk assessment, we study the characteristics of the spectral amplitude decay of $S$-waves with distance using small to moderate earthquakes recorded at stations of the Basilicata seismic network of Southern Italy.

In a previous study, Castro et al. (1999) obtained average Nonparametric Attenuation Func- tions (hereafter referred to as NAF) using seismic records from other regions of Italy. In this paper we will use those NAF as a reference frame to compare the attenuation characteristics in Southern Italy.

\section{Data}

We analyzed horizontal component records from 32 earthquakes with magnitudes $M_{L}=2.0$ 5.4 recorded by four stations of the Basilicata

Table I. Earthquake coordinates and hypocentral distances.

\begin{tabular}{|c|c|c|c|c|c|c|c|c|c|c|}
\hline No. & $\begin{array}{c}\text { Date } \\
\text { D.M.Yr }\end{array}$ & $\begin{array}{c}\text { Origin } \\
\text { Hr.Min.S }\end{array}$ & $\begin{array}{l}\text { Lat. } \\
\text { Deg. }\end{array}$ & $\begin{array}{l}\text { Long. } \\
\text { Deg. }\end{array}$ & $M_{L}$ & $\begin{array}{c}\text { Depth } \\
\text { km }\end{array}$ & $\begin{array}{c}\text { VEN } \\
\mathrm{km}\end{array}$ & $\begin{array}{c}\text { MAT } \\
\mathrm{km}\end{array}$ & $\begin{array}{l}\text { TIT } \\
\mathrm{km}\end{array}$ & $\begin{array}{l}\text { VIL } \\
\mathrm{km}\end{array}$ \\
\hline 2 & 14.09 .01 & 08.01 .49 & 40.664 & 15.741 & 2.0 & 10 & & 73.00 & 12.00 & 34.00 \\
\hline 5 & 20.11 .01 & 18.29 .03 & 41.468 & 15.676 & 3.4 & 11 & 58.00 & 120.00 & 97.00 & 123.00 \\
\hline 6 & 21.11 .01 & 06.10 .40 & 40.507 & 15.799 & 2.8 & 20 & 55.00 & 72.00 & 23.00 & 25.00 \\
\hline 7 & 21.11 .01 & 06.20 .54 & 40.520 & 15.809 & 2.7 & 11 & & 69.00 & 16.00 & 20.00 \\
\hline 8 & 30.11 .01 & 03.17 .37 & 41.751 & 15.860 & 3.4 & 12 & 88.00 & 138.00 & 129.00 & 153.00 \\
\hline 9 & 09.12 .01 & 12.15 .21 & 40.786 & 15.348 & 2.8 & 9 & 41.00 & 103.00 & 36.00 & \\
\hline 12 & 02.01 .02 & 02.17 .08 & 40.753 & 15.429 & 2.8 & 11 & 39.00 & & 30.00 & 52.00 \\
\hline 13 & 15.01 .02 & 00.07 .07 & 40.737 & 15.801 & 2.6 & 7 & 27.00 & 69.00 & 18.00 & \\
\hline 14 & 15.01 .02 & 01.29 .16 & 40.734 & 15.796 & 2.4 & 9 & 27.00 & 69.00 & 18.00 & \\
\hline 19 & 06.04 .02 & 06.35 .23 & 39.224 & 16.544 & 2.9 & 5 & 201.00 & 159.00 & & 139.00 \\
\hline 20 & 05.04 .02 & 14.54 .07 & 39.144 & 16.804 & 3.8 & 10 & 216.00 & 168.00 & & 156.00 \\
\hline 22 & 13.04 .02 & 17.04 .12 & 40.569 & 16.394 & 3.3 & 6 & 62.00 & 26.00 & 51.00 & 50.00 \\
\hline 23 & 18.04 .02 & 20.56 .47 & 40.612 & 15.594 & 4.1 & 5 & 43.00 & 84.00 & 11.00 & 31.00 \\
\hline 24 & 18.04 .02 & 21.00 .34 & 40.583 & 15.516 & 3.2 & 9 & 49.00 & & 18.00 & 33.00 \\
\hline 25 & 18.04 .02 & 21.36 .52 & 40.569 & 15.524 & 3.1 & 5 & 50.00 & & 16.00 & 31.00 \\
\hline 26 & 18.04 .02 & 22.58 .31 & 40.577 & 15.547 & 3.0 & 7 & 48.00 & 87.00 & 18.00 & 31.00 \\
\hline 27 & 18.04 .02 & 23.19 .06 & 40.572 & 15.524 & 3.1 & 8 & 50.00 & & 15.00 & 32.00 \\
\hline 29 & 21.04 .02 & 23.39 .19 & 40.569 & 15.580 & 3.5 & 10 & & 85.00 & 15.00 & 28.00 \\
\hline 36 & 31.10 .02 & 11.34 .42 & 41.760 & 14.940 & 5.4 & 10 & 110.00 & 181.00 & 142.00 & 167.00 \\
\hline 37 & 31.10 .02 & 11.56 .22 & 41.710 & 14.825 & 3.5 & 10 & 112.00 & 184.00 & & 167.00 \\
\hline 38 & 31.10 .02 & 13.04 .11 & 41.670 & 14.890 & 3.7 & 10 & 105.00 & 177.00 & 134.00 & 160.00 \\
\hline 41 & 01.11 .02 & 15.09 .15 & 41.690 & 14.830 & 5.3 & 10 & 109.00 & 184.00 & 139.00 & 164.00 \\
\hline 42 & 01.11 .02 & 15.20 .04 & 41.740 & 14.850 & 4.1 & 10 & 113.00 & & 143.00 & 168.00 \\
\hline 43 & 01.11 .02 & 15.42 .23 & 41.720 & 14.840 & 3.4 & 10 & 111.00 & 184.00 & & 166.00 \\
\hline 45 & 01.11 .02 & 17.21 .15 & 41.710 & 14.810 & 4.3 & 10 & 112.00 & & 141.00 & 166.00 \\
\hline 46 & 01.11 .02 & 22.30 .26 & 41.720 & 14.850 & 3.1 & 10 & 111.00 & 183.00 & & 166.00 \\
\hline 47 & 01.11 .02 & 22.44 .13 & 41.690 & 14.800 & 3.8 & 10 & 111.00 & 184.00 & 140.00 & 165.00 \\
\hline 48 & 02.11 .02 & 02.36 .27 & 41.720 & 14.810 & 3.7 & 10 & 113.00 & 186.00 & & 167.00 \\
\hline 49 & 02.11 .02 & 06.22 .06 & 41.690 & 14.810 & 3.8 & 10 & 110.00 & 183.00 & & 164.00 \\
\hline 50 & 03.02 .03 & 11.24 .24 & 40.760 & 15.538 & 3.1 & 10 & 33.00 & 89.00 & 25.00 & 48.00 \\
\hline 51 & 03.02 .03 & 12.18 .39 & 40.760 & 15.538 & 2.7 & 10 & 33.00 & 89.00 & 25.00 & 48.00 \\
\hline 52 & 04.02 .03 & 08.31 .33 & 40.740 & 16.240 & 2.5 & 10 & 41.00 & 38.00 & 43.00 & 54.00 \\
\hline
\end{tabular}




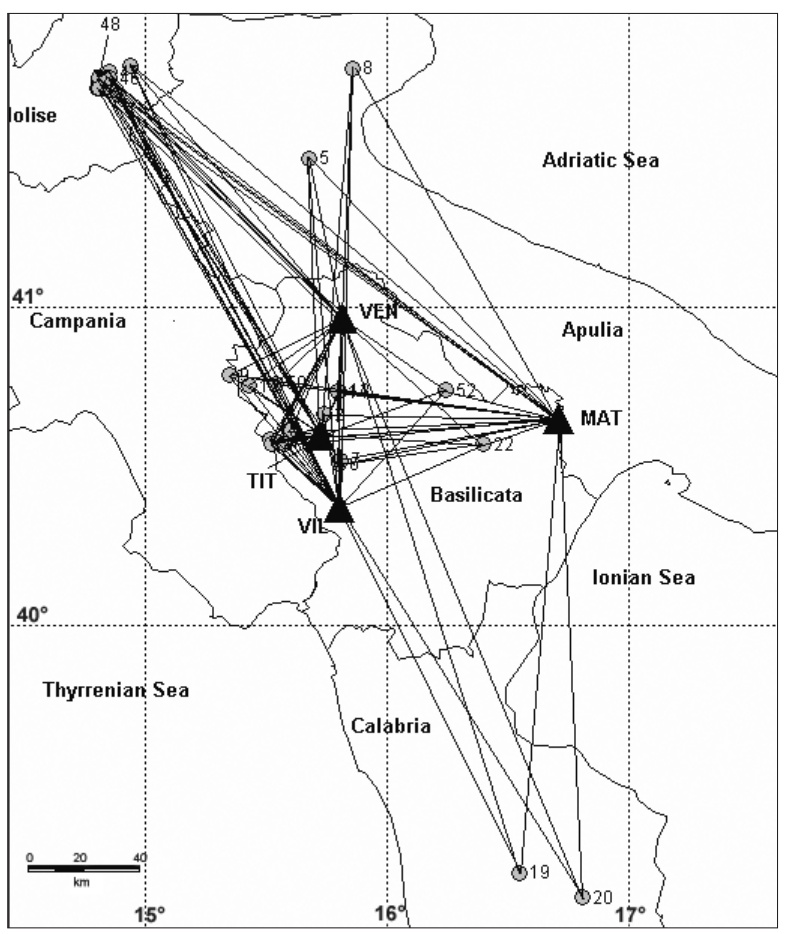

Fig. 1. Location of earthquakes and seismic stations used. The circles with identification number are the epicenters (see also table I) and the triangles are the location of the stations. We also draw the source-station paths.

seismic network. The network was set up by the Institute for Methodology of Environmental Analysis of the National Research Council and the Department of Structure, Soil Mechanics and Engineering Geology of the University of Basilicata in the framework of a multiparametric geophysical observatory (Balasco et al., 2001). All the stations are equipped with $1 \mathrm{~Hz}$ tridirectional seismometers (Lennartz $3 \mathrm{~d}$ Lite at VEN, VIL, MAT and Mark L4C at TIT) connected to 24 bit A/D converter (PRAXS) with an instrument response approximately constant between 1 and $25 \mathrm{~Hz}$.

Table I lists the epicentral coordinates of the events used and the hypocentral distances to the recording stations. The distribution of the epicenters and the location of the seismic stations are also displayed in fig. 1. The source-station paths cover mainly the southern end of the Apennines and northeast of Calabria, Italy. The

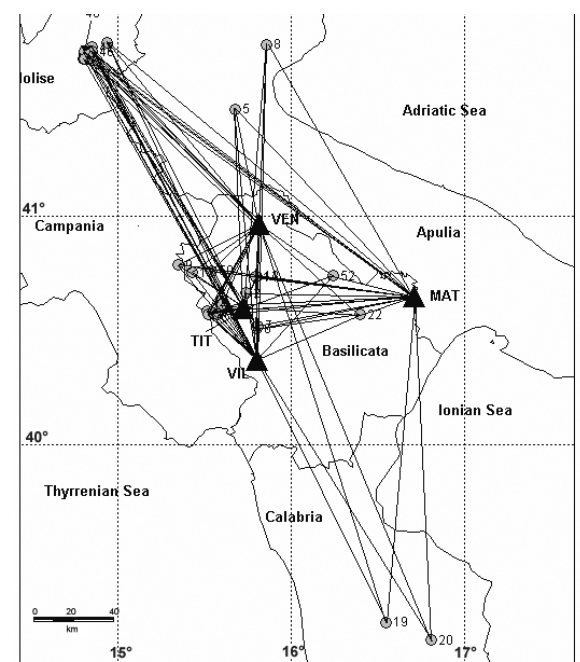

Fig. 2. Hypocentral distance versus magnitude distribution of velocity records used. 
hypocentral coordinates were taken from the Seismic Bulletin of the Italian National Institute of Geophysics and Volcanology (INGV). Events 36 to 49 in table I are events of the Molise seismic sequence of 2002 that caused damage in San Giuliano (Mucciarelli et al., 2003a). In particular, events 36 and 41 are the main events of the sequence that generated intensity up to VIII-IX MCS in San Giuliano. According to the information reported by the IN$\mathrm{GV}$ Bulletin the focal depth of these events and events 50-52 was fixed at $10 \mathrm{~km}$. The distancemagnitude distribution of the records, plotted in fig. 2, shows that most of the data is in the ranges of $M<4.0$ and $r<180 \mathrm{~km}$.

The records were base line corrected subtracting the average of all the points of the record. Then we calculated the acceleration spectra using a time window containing the first $S$-wave arrivals. The beginning of the window was chosen at the first $S$ arrival and the end when $80 \%$ of the total energy was reached, the window was also cosine tapered. The accelera- tion spectra were instrument corrected and smoothed around 14 pre-selected frequencies $(1.0<f<20 \mathrm{~Hz})$. We visually selected, for each spectral record, the frequency band with the highest signal to noise ratio. The frequency at which the spectra became flat (in a semi-logarithmetic plot) was chosen as the end of the frequency band. The same procedure was used to estimate NAF in other regions of Italy (Castro et al., 1999). Figure 3 shows four examples of the frequency window selected for further analysis. For most of the records the spectral amplitude flattens beyond $25 \mathrm{~Hz}$.

Figure 4 displays velocity records from an earthquake $M=3.0$ used in the analyses. This figure shows the time windows selected to calculate the acceleration spectra of pre-event noise and $S$-wave signal as well. In general, the signal to noise ratio is at least a factor of 10 between 1-10 Hz. At higher frequencies the ratio remains high for stations VIL and MAT, and for stations TIT and VEN the spectral amplitude of the noise approaches that of the $S$-wave at $f>18$
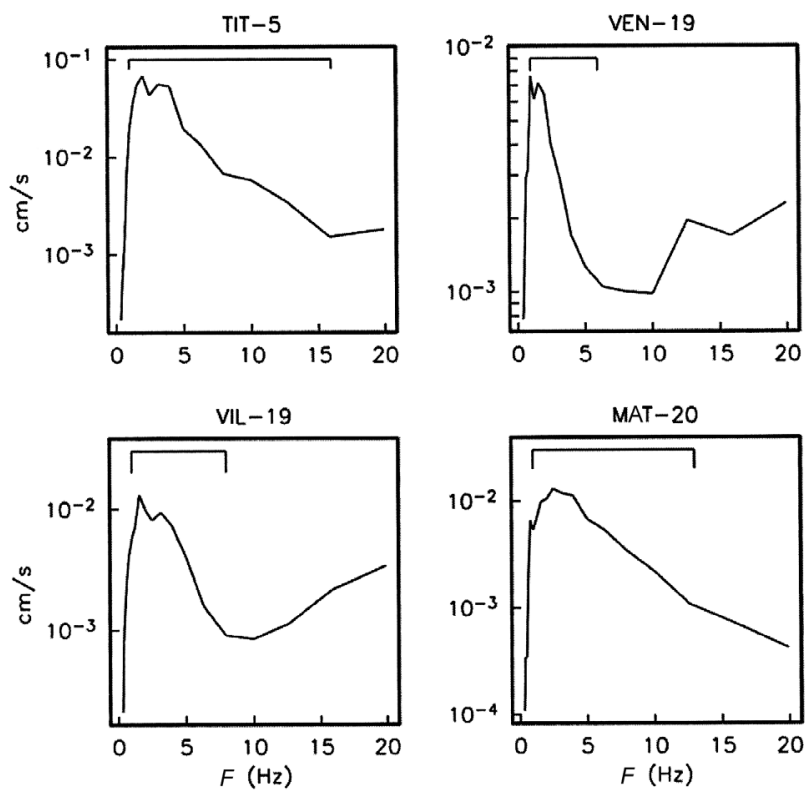

Fig. 3. Examples of acceleration spectra and the frequency band used. The frequency band used for further analysis is shown with brackets. 

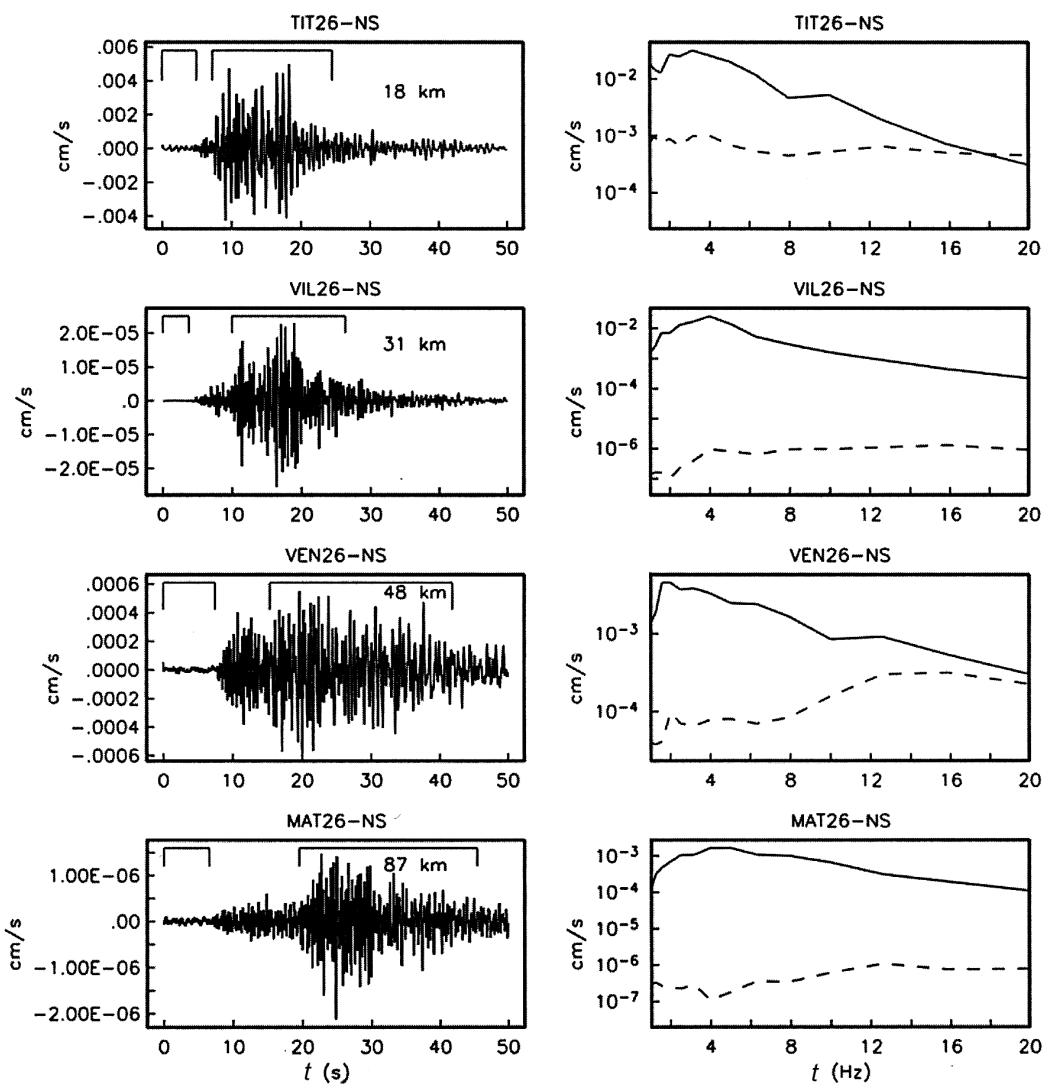

Fig. 4. The frames on the left show the velocity records from event 26 as recorded for the four stations used. The time series are order from minimum distance (top frame) to maximum hypocentral distance. It is also shown the window use to calculate the Fourier transform. The frames on the right are the corresponding acceleration spectra of the $S$-wave signal (solid line) and the pre-event noise (dashed lines).

Hz. We can infer from the spectral inspection of the spectral records that the quality of the data set is very good up to $10 \mathrm{~Hz}$ for all the stations used and up to $25 \mathrm{~Hz}$ for VIL and MAT.

\section{Method}

We model the spectral amplitude decay with hypocentral distance $r$ for each sampled frequency using a nonparametric approach. We assumed that the observed spectral amplitude $U_{i}(r, f)$ at frequency $f$ depends on the size of the earthquake that can be represented by a scalar $S_{i}$, and the at- tenuation due to geometrical spreading and anelasticity of the medium. Thus, we can write

$$
U_{i}(r, f)=S_{i} \cdot A(r, f) .
$$

In eq. (3.1) the attenuation function $A(r, f)$ is the same for all source-station paths and is not limited to have a particular functional form. The site effects are eliminated using a smoothing constraint and by making $A(0, f)=1.0$, since at $r=0$ only the source term controls the value of the spectral amplitude. We calculated independent inversions for 14 different frequencies between 1.0 and $20 \mathrm{~Hz}$. The distance range 
from $5 \mathrm{~km}$ to $200 \mathrm{~km}$ was discretized into 40 bins, $5 \mathrm{~km}$ wide. Anderson and Quaas (1988) and Castro et al. $(1990,1999)$ used this nonparametric model before to describe the amplitude decay in other regions.

\section{Results}

Figure 5 shows a sample of 6 attenuation functions obtained between 1 and $20 \mathrm{~Hz}$. For comparison we also plotted with different symbols the observed amplitudes, circles for event $5(M=3.4)$ and asterisks for event $8(M=3.4)$. The curves shown are scaled accordingly with the corresponding value of $S_{i}$. The functions obtained show a change in the rate of amplitude decay at $r>100 \mathrm{~km}$ probably due to the effect of geometrical spreading, which for that distance range is less severe. It is also noticeable that at $f>10 \mathrm{~Hz}$ the scatter of the data tends to increase, perhaps as a result of site effects. For some of the sites used, Mucciarelli et al. (2003b) observed that site effect is a remarkable and stable feature. At high frequencies $(f>10 \mathrm{~Hz})$ the near-site attenuation $\left(\kappa_{0}\right)$ can also explain the observed scatter.
In order to evaluate how the NAF of Southern Italy compare with those for other regions of Italy, we plot them in fig. 6 (with circles) together with the average attenuation functions obtained by Castro et al. (1999) (solid lines) \pm 1 standard deviation (dashed lines). The NAF reported for Castro et al. (1999) were obtained averaging attenuation functions from the regions of Lombardy, Piedmont, Eastern Sicily, Friuli and Marche. At $1 \mathrm{~Hz}$ the NAF of Southern Italy (circles) are slightly below the standard deviation of the average, but in general at low frequencies $(f<5 \mathrm{~Hz})$ the attenuation is stronger than the average. At high frequencies $(f>5 \mathrm{~Hz})$ attenuation in Southern Italy is minor than the average, and at higher frequencies $(f>10 \mathrm{~Hz})$ the NAF are slightly above the standard deviation of the average.

The frequency dependence of the attenuation can be appreciated in fig. 7, where we compared NAF between 2 and $10 \mathrm{~Hz}$. It can be seen in this figure that for a given distance $r$ the $S$ wave attenuation factor tends to decrease with frequency.

The NAF obtained can be also quantified in terms of the quality factor $Q$ and the geometrical spreading. For this purpose, we can parame-
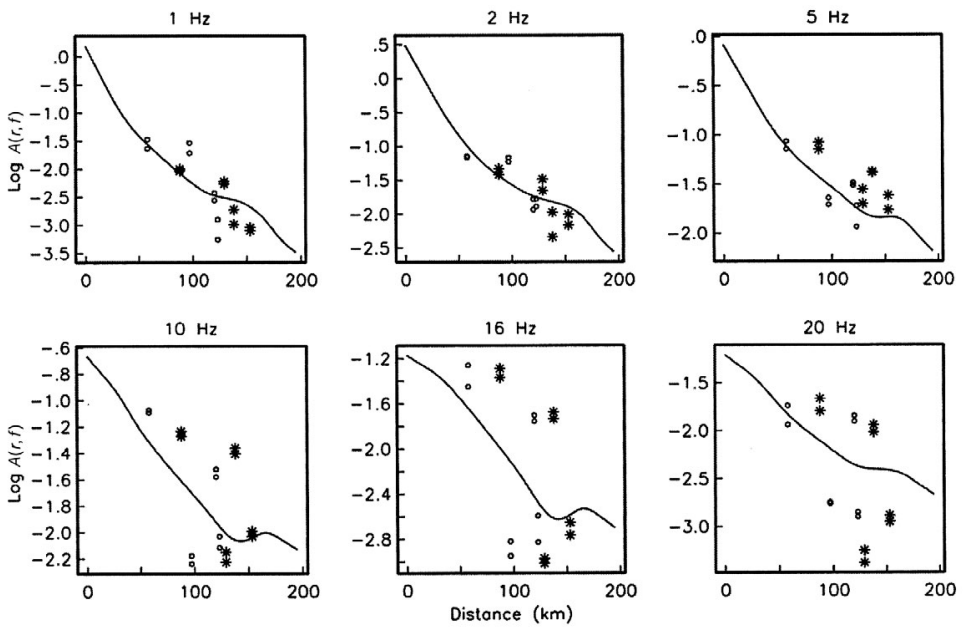

Fig. 5. Nonparametric attenuation functions obtained (solid lines) and observed spectral amplitudes from event 5 (circles) and from event 8 (asterisks). 

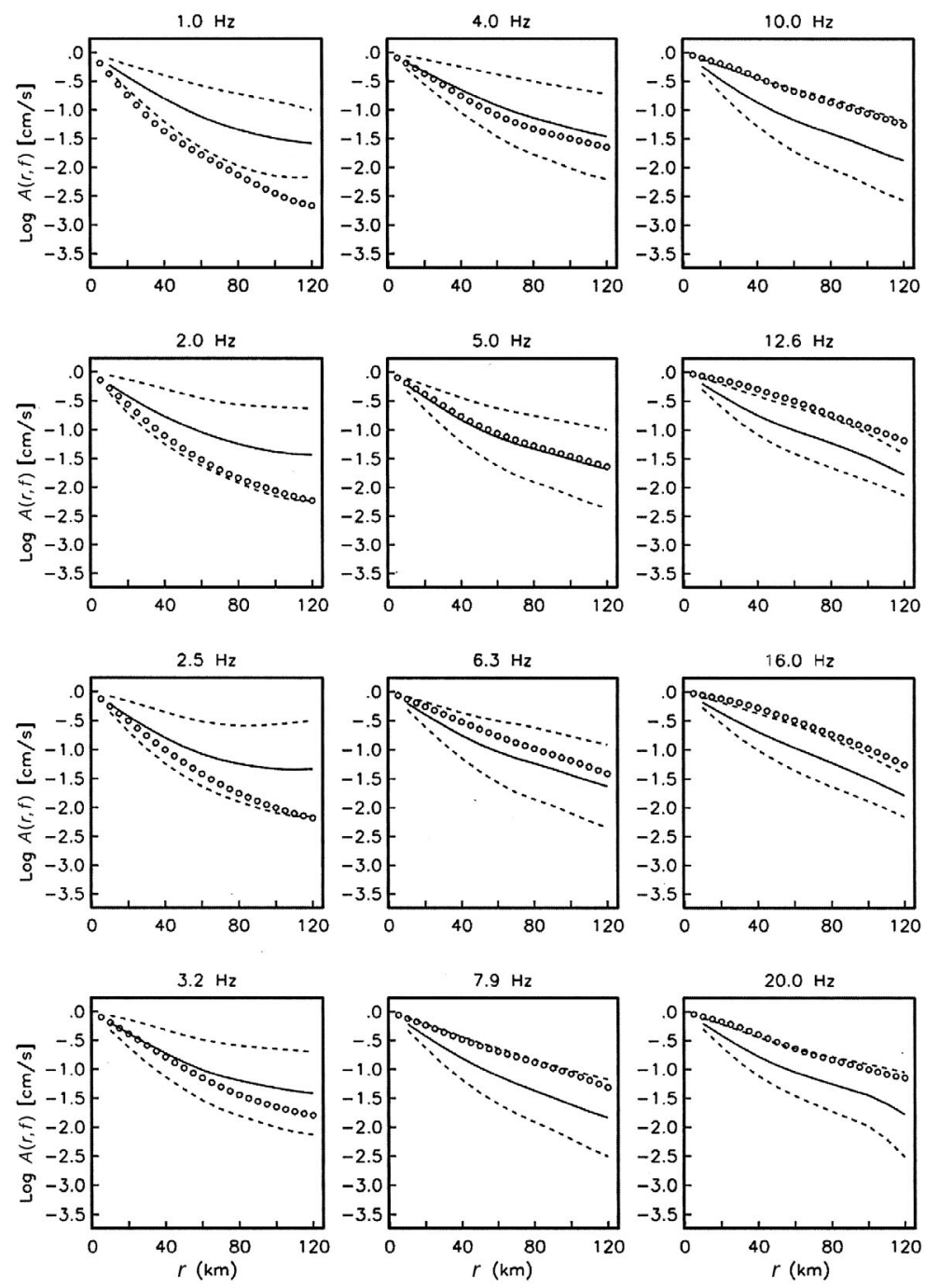

Fig. 6. Average NAF (solid lines) and \pm 1 standard deviation (dashed lines) obtained by Castro et al. (1999) from different regions of Italy and the attenuation functions obtained for Southern Italy (this study).

terize the attenuation functions as

$$
A(f, r)=\frac{10}{r^{b}} \cdot e^{-\pi f R l Q \beta} .
$$

Where $G(r)=10 / r^{b}$ accounts for the geometrical spreading, $R=(r-10), Q$ is the quality factor of the $S$-waves and $\beta=3.2 \mathrm{~km} / \mathrm{s}$. Note that eq. (4.1) is normalized at $10 \mathrm{~km}$, because we do not have information at closer hypocentral distances (see fig. 2). We only considered the NAF at frequencies where the instrument response is constant $(f \geq 1.6 \mathrm{~Hz})$ and the specific near-surface attenuation at each site is less severe $(f \leq 10 \mathrm{~Hz})$. We also used only the distance 
range where the effect of site response and reflected waves is minimum $(r \leq 120 \mathrm{~km})$.

We linearized eq. (4.1) by taking logarithms, thus we can write,

$$
a(r)=-m r
$$

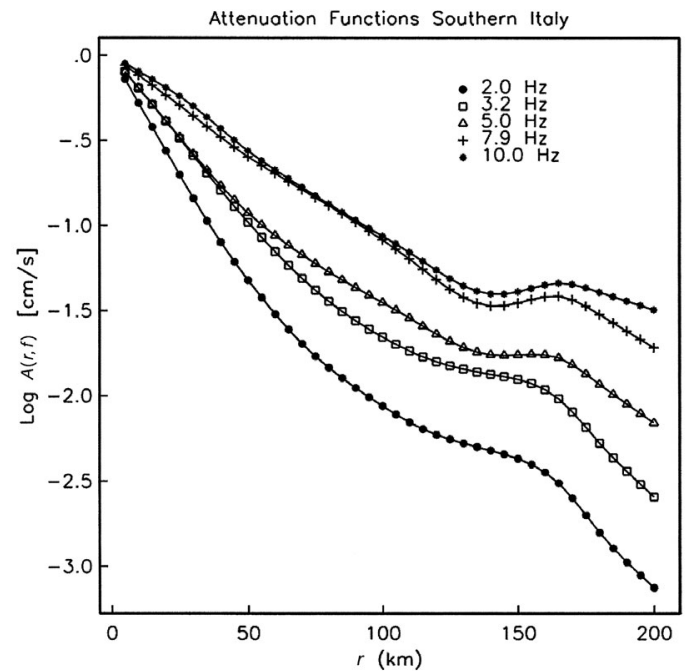

Fig. 7. A sample of NAF obtained for frequencies between 2 and $10 \mathrm{~Hz}$.
Where $a(r)=\log A(f, r)-\log G(r)$ and $m=\pi f$. $\cdot \log e / Q \beta$. For each frequency $f$, we searched for values of $b$ and $m$ that give the best leastsquares solution of eq. (4.2) (e.g., Castro et al., 2003).

Figure 8 and table II show the resulting values of the exponent $b$ and $Q$ for the frequency band analyzed $(1.6 \leq f \leq 10.0 \mathrm{~Hz})$. The values of $Q$ (triangles in fig. 8) show stronger frequency dependence than the exponent $b$ of the geometrical spreading function. For comparison, we also plotted in fig. 8 (asterisks) recent estimates of coda $Q(Q c)$ obtained by Bianco et al. (2002) for the Southern Apennine zone. Between $3 \mathrm{~Hz}$ and $5 \mathrm{~Hz}$ the values of $Q c$ are similar to those obtained using $S$-waves (triangles); at higher frequencies $(f>5 \mathrm{~Hz}) Q c$ has lower values (56$59 \%$ lower). $b$ is approximately $1.0 \pm 0.2$, so that $G(r) \approx 1 / r$, as is expected for body waves. The following relation can approximate the frequency dependence of $Q$ :

$$
Q=32.1 f^{1.7} \text {. }
$$

Because of the trade-off between $Q$ and the geometrical spreading function, it is more meaningful to compare the combined effect of $Q$ and $G(r)$ together. In fig. 9 we compare the nonparametric attenuation functions (open circles) with the spectral amplitude decay predicted by eq. (4.1) using the values listed in table II
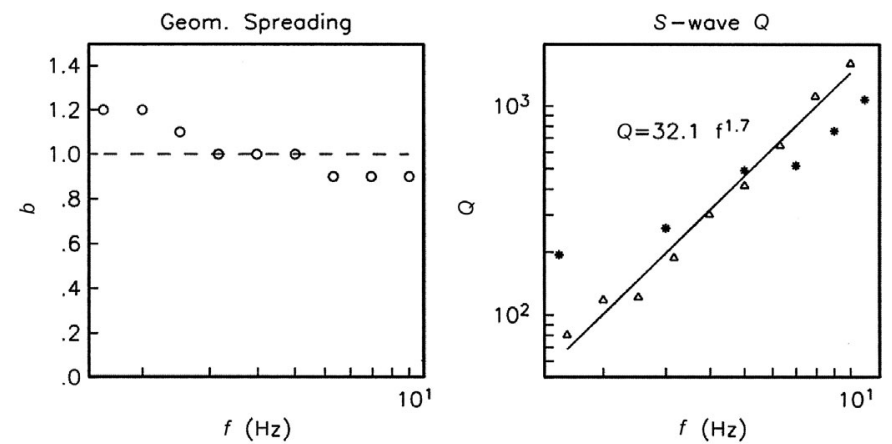

Fig. 8. Left frame shows the values of the exponent $b$ obtained for the geometrical spreading function assumed (see eq. (4.1)). The right frame shows the estimates of the quality factor $Q$ - of the $S$-waves (triangles) as function of frequency. The asterisks are the values of coda $Q$ reported by Bianco et al. (2002) for the Southern Apennine zone. 
(solid line in fig. 9). In this figure we also compare other parametric relations reported in the literature and that describe the amplitude decay with distance of $S$-waves (see also table III). In table III we did not list estimates of coda $Q$, as

Table II. Resulting parameters of eq. (4.1).

\begin{tabular}{ccc}
\hline \hline$f(\mathrm{~Hz})$ & $b$ & $Q$ \\
\hline 1.6 & 1.2 & 80 \\
2.0 & 1.2 & 118 \\
2.5 & 1.1 & 121 \\
3.2 & 1.0 & 188 \\
4.0 & 1.0 & 302 \\
5.0 & 1.0 & 413 \\
6.3 & 0.9 & 643 \\
7.9 & 0.9 & 1112 \\
10.0 & 0.9 & 1608 \\
\hline
\end{tabular}

those reported by Del Pezzo and Zollo (1984), Del Pezzo and Scarcella (1986), Bindi et al. (2001) and others, but those are compared and discussed by Castro et al. (2002). The dotted lines in fig. 9 correspond to the amplitude decay calculated using the attenuation model of Rovelli et al. (1988)

$$
A(f, r)=\frac{1}{r} \cdot \exp \left(-\pi \kappa_{0} f\right) \cdot \exp \left(-\frac{\pi r}{\beta Q_{0}}\right)
$$

Where $\kappa_{0}=0.07, \beta=3.2 \mathrm{~km} / \mathrm{s}$, and $Q_{0}=100$. The dashed lines correspond to the attenuation curves proposed by Malagnini et al. (2000) for the entire Apennines (see table III). This curves are characterized for having significant discontinuities at 30 and $80 \mathrm{~km}$ that are possibly related to the complex crustal structure of the Apennines. It is interesting to note that at $3.2 \mathrm{~Hz}$ and $r>80 \mathrm{~km}$ the attenuation curves of Malagnini et al. (2000) are the same as those calculated
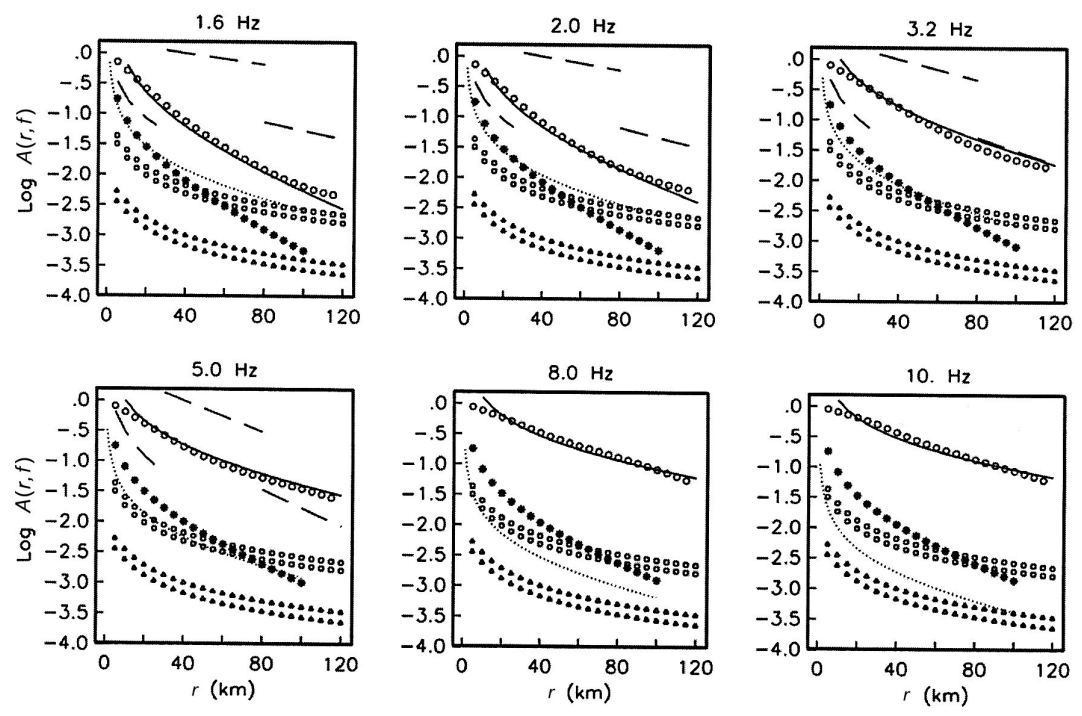

Fig. 9. Parametric Attenuation Functions (PAF) reported in different regions of Italy. The nonparametric functions obtained in this study are plotted with open circles. The solid lines are the attenuation functions calculated with eq. (4.1) using the values listed in table III. The dashed lines are the PAF calculated with the $Q$ and $G(r)$ obtained by Malagnini et al. (2000) (see table III). The dotted curves are the PAF reported by Rovelli et al. (1988) (eq. (4.4)).The asterisks are the PAF of Castro et al. (2003b). The squares and the triangles are the PGA and PGV attenuation functions, respectively, of Sabetta and Pugliese (1987) (eqs. (4.5) and (4.6)). 
Table III. $S$-wave attenuation relations reported for Italy.

\begin{tabular}{cccccc}
\hline \hline Region & $\begin{array}{c}\text { Distance } \\
\text { range }(\mathrm{km})\end{array}$ & $\begin{array}{c}\text { Frequency } \\
\text { range }(\mathrm{Hz})\end{array}$ & $Q$ & $\begin{array}{c}\text { Geometrical } \\
\text { spreading }\end{array}$ & Reference \\
\hline $\begin{array}{c}\text { Central and } \\
\begin{array}{c}\text { Central-Southern } \\
\text { Apennines }\end{array}\end{array}$ & $r \leq 100$ & $0.1 \leq f \leq 20$. & $\begin{array}{c}Q=100 \\
\text { and } \kappa_{0}=0.07\end{array}$ & $\frac{1}{r}$ & Rovelli et al. (1988) \\
$\begin{array}{c}\text { Entire Apennines } \\
\text { Embria-Marche }\end{array}$ & $r \leq 100$ & $0.3 \leq f \leq 9.5$ & $Q=31.2 f^{1.2}$ & $\begin{array}{c}r^{-0.5}, r \geq 80 \mathrm{~km} \\
r^{-0.9}, r \leq 30 \mathrm{~km}\end{array}$ & Malagnini et al. (2000) \\
Southern Italy & $r \leq 120$ & $1.6 \leq f \leq 10$ & $Q=32.1 f^{1.7}$ & $\frac{10}{r^{b}}, b=1.0 \pm 0.2$ & Castro et al. (2003a) \\
\hline
\end{tabular}

with eq. (4.1). The asterisks in fig. 9 are the attenuation functions calculated using the relation obtained by Castro et al. (2004) for Central Italy, namely $Q=31.2 f^{1.2}$ in the frequency band of $0.3-9.5 \mathrm{~Hz}$ and $G(r)=1 / r$. These curves are similar to those calculated with the model of Rovelli et al. (1988) at short distances $(r<40$ $\mathrm{km})$ in the frequency band of 1.6-3.2 Hz. It is important to keep in mind, when comparing these attenuation functions, that the data used to obtain them sampled not only different frequency bands but also different crustal volumes. For instance, while the data set used by Malagnini et al. (2000) sampled the entire Apennines, our results are only valid for Southern Italy.

Because these attenuation functions may have an important impact in the estimation of Peak Ground Acceleration (PGA) and Peak Ground Velocity (PGV), we also compare the empirical relations obtained by Sabetta and Pugliese (1987) to estimate PGA and PGV in Italy from magnitude $(M)$, site type $(S=0$ for rock and $S=1$ for soil) and the closest distance to surface projection of the fault rupture $(R)$

$\log P G A=-1.562-\log \left(R^{2}+5.8^{2}\right)^{1 / 2}+0.169 S+$ $+0.306 M$

$\log P G V=-0.710-\log \left(\mathrm{R}^{2}+3.6^{2}\right)^{1 / 2}+0.133 S+$ $+0.455 M$.

We plotted in fig. 9 the first 3 terms of eqs. (4.5) and (4.6), with triangles and squares respectively, using both $S=1$ and $S=0$. The PGA relation (triangles) gives higher attenuation factors at low frequencies relative to the other curves. However, at $10 \mathrm{~Hz}$ and $r>80 \mathrm{~km}$ the PGA curve approaches the moel of Rovelli et al. (1988). On the other hand, the PGV curve approaches the model of Rovelli et al. (1988) between 3.2 and $5.0 \mathrm{~Hz}$. It is important to point out that $\mathrm{Sa}-$ betta and Pugliese (1987) and Rovelli et al. (1988) used similar data sets, namely, records from the earthquakes of Valerina, 1979; Irpinia, 1980; Umbria, 1984 and Lazio-Abruzzo, 1984. Sabetta and Pugliese (1987) also included events from the regions of Friuli and Sicily.

The result of comparing the parametric attenuation functions reported (fig. 9 and table III) indicates that a significant spatial variability of the attenuation parameters $Q$ and $G(r)$ must exist in Italy. This variability must be the result of a heterogeneous complex crustal structure. Spatial variability of $Q$ can be significant, particularly near seismogenic zones (Castro et al., 2000). Li et al. (1997), for instance, found a reduction of $S$-wave velocity (30-50\%) and $Q$ within tens of meters of the fault trace at Parkfield, California. Changes in the geologic characteristics of the rocks are also responsible for the spatial variability of $Q$. Thus, we can expect different behavior of $Q$ and $G(r)$ for different $S$-wave propagation crustal volumes. 


\section{Conclusions}

We determined nonparametric attenuation functions for 14 frequencies $(1.0<f<20.0 \mathrm{~Hz})$. At low frequencies $(f<5.0 \mathrm{~Hz})$ these functions show a faster decay than those obtained by Castro et al. (1999) averaging NAF from different regions of Italy. However, at intermediate frequencies $(f>5.0 \mathrm{~Hz})$ the spectral amplitudes are above the average, and at higher frequencies $(f>10 \mathrm{~Hz})$ the attenuation functions obtained for Southern Italy are slightly above the standard deviation of the average functions. The data set used in this frequency band $(f>10 \mathrm{~Hz})$ may be affected by stronger site effects than expected, in particular near-surface attenuation may have a strong effect on the spectral amplitudes at high frequencies.

We also estimated the quality factor $Q$ of the $S$-waves using a parametric approach and we found that $Q$ shows a frequency dependence that can be approximated by the function $Q=32.1 f^{1.7},(1.6 \leq f \leq 10.0 \mathrm{~Hz})$ and $\mathrm{G}(r)=10 / r^{b}$, $(b=1.0 \pm 0.2)$. This parametric model of $S$-wave attenuation shows significant differences with respect to attenuation models reported for neighboring regions (Sabetta and Pugliese, 1987; Rovelli et al., 1988; Malagnini et al., 2000). This indicates that a significant spatial variability of the attenuation parameters $Q$ and $G(r)$ exists in Italy.

Further developments of this work will include separation of ray-paths crossing mainly the Apennines and those crossing the Apulian plate. When enough data are available, it will be interesting to verify whether the Apulian plate is less attenuating than the Apennines, as geodynamic models predict.

\section{Acknowledgements}

The Basilicata network was set up and maintained thanks to grants of the Italian Ministry for University and Research. Many thanks to Dr. Enzo Lapenna from the IMAA-CNR for his constant help. We also acknowledge Luca Malagnini and the anonymous reviewer for their comments and suggestions. Luis Inzunza help us preparing the figures.

\section{REFERENCES}

Anderson, J.G. and R. QuAas (1988): The Mexico earthquake of September 19, 1985: effect of magnitude on the character of strong ground motion: an example from the Guerrero, Mexico strong motion network, Earthquake Spectra, 4, 635-646.

Balasco, M., D. Chianese, V. Cuomo, G. Di Bello, M.R. GALliPOLI, V. LAPENNA and M. MuCCIARELli (2001): Design of a new prototype of remote station to detect electrical and seismometric parameters in a seismic area of Southern Italy, Phys. Chem. Earth, 26 (10/12), 787-791.

Bianco, F, E. Del Pezzo, M. Castellano, J. Ibanes and F. Di Luccio (2002): Separation of intrinsic and scattering seismic attenuation in the Southern Apennine zone, Italy, Geophys. J. Int., 150, 10-22.

Bindi, D., D. Spallarossa, P. Augliera and M. Cattaneo (2001): Source parameters estimated from the aftershocks of the 1997 Umbria-Marche (Italy) seismic sequence, Bull. Seismol. Soc. Am., 91, 448-455.

Caputo, M., G.F. PAnZa and D. Postpischl (1972): New evidences about deep structure of the Lipari Arc, Tectonophysics, 15, 219-231.

Castro, R.R., J.G. Anderson and S.K. Singh (1990): Site response, attenuation and source spectra of $S$-waves along the Guerrero, Mexico, subduction zone, Bull. Seismol. Soc. Am., 80, 1481-1503.

Castro, R.R., M. Mucciarelli, G. Monachesi, F. Pacor and R. BERARDI (1999): A review of nonparametric attenuation functions computed for different regions of Italy, Ann. Geofis., 42 (4), 735-748.

Castro, R.R., L. Trojani, G. Monachesi, M. MucciarelLI and M. CATTANEO (2000): The spectral decay parameter in the region of Umbria-Marche, Italy, J. Geophys. Res., 105, 23,811-23,823.

Castro, R.R., M. Monachesi, L. Trojani, M. MucciarelLI and M. FrAPICCINI (2002): An attenuation study using earthquakes from the 1997 Umbria-Marche sequence, J. Seismol., 6, 43-59.

CAstro, R.R., H. Fabriol, M. Bour and B. Le Brun (2003): Attenuation and site effects in the region of Guadeloupe, Lesser Antilles, Bull. Seismol. Soc. Am., 93 (2), 612-626.

Castro, R.R., F. Pacor, D. Bindi, G. Franceschina and L. LUZI (2004): Site response of strong motion stations in the Umbria, Central Italy, Region, Bull. Seismol. Soc. Am., 94 (2), 576-590.

Del Pezzo, E. and G. Scarcella (1986): Three component coda $Q$ in the Abruzzi-Molise region, Central Appenines, Ann. Geophysicae, 5, 589-592.

Del Pezzo, E. and A. Zollo (1984): Attenuation of coda waves and turbidity coefficient in Central Italy, Bull. Seismol. Soc. Am., 74, 2665-2659.

Del Pezzo, E., G. Luongo and R. Scarpa (1979): Seismic wave transmission in Southern Tyrrhenian Sea, Boll. Geofis. Teor. Appl., 21, 53-65.

Gasparini, C., G. IANNACCONE, P. SCANDONE and R. SCARPA (1982): Seismotectonics of the Calabrian Arc, Tectonophysics, 84, 267-286.

Li, Y.G., W.L. Ellsworth, C.H. Thurber, P.E. Malin and K. AKI (1997): Fault-zone guided waves from explosions in the San Andreas Fault at Parkfield and Cienega Valley, California, Bull. Seismol. Soc. Am., 87, 210-221. 
Malagnini, L., R.B. Herrmann and M. Di Bona (2000): Ground-motion scaling in the Apennines (Italy), Bull. Seismol. Soc. Am., 90 (4), 1062-1081.

Mantovani, E., D. Albarello, C. Tamburelli and D. BABBUCCI (1996): Evolution of Tyrrhenian Basin and surrounding regions as a result of the Africa-Eurasia convergence, J. Geodyn., 21 (1), 35-72.

McKenZIE, D. (1972): Active tectonics of the Mediterranean region, Geophys. J. R. Astron. Soc., 30, 109-185.

Mele, G., A. Rovelli, D. Seber and M. Barazangi (1997): Shear wave attenuation in the lithosphere beneath Italy and surrounding regions: tectonic implications, J. Geophys. Res., 102, 11, 863-11,875.

Mucciarelli, M., A. Masi, M. Vona, M.R. Gallipoli, P Harabaglia, R. Caputo, S. Piscitelli, E. Rizzo, M. Picozzi, D. Albarello and C. LizZa (2003a): Quick survey of the possible causes of damage enhancement observed in San Giuliano after the 2002 Molise, Italy seismic sequence, J. Earthquake Eng., 7, 1-17.
Mucciarelli, M., M.R. Gallipoli and M. Arcier (2003b): Stability of horizontal-to-vertical spectral ratio by triggered noise and earthquake recordings, Bull. Seismol. Soc. Am., 93 (3), 1407-1412.

Rovelli, A., O. Bonamassa, M. Cocco, M. Di Bona and S. MAzZA (1988): Scaling laws and spectral parameters of the ground motion in active extensional areas in Italy, Bull. Seismol. Soc. Am., 78 (2), 530-560.

Sabetta, F., and A. Pugliese (1987): Attenuation of peak horizontal acceleration and velocity from Italian strong-motion records, Bull. Seismol. Soc. Am., 77 (5), 1491-1511.

VAlensise, G. and D. Pantosti (2001): The investigation of potential earthquake sources in peninsular Italy: a review, J. Seismol., 5, 287-306.

(received October 13, 2003; accepted February 12, 2004) 